\title{
Timeline: a decade of advances in immunotherapy
}

\author{
Drew Pardoll
}

PD-1 knockout mice develop autoimmune syndromes, suggesting that the receptor PD-1 is an immune checkpoint ${ }^{1,2}$.

Two ligands for PD-1 are identified: B7-H1 (also known as PD-L1) and B7-DC (also known as PD-L2) ${ }^{3-5}$.

$\mathrm{B} 7-\mathrm{H} 1$ is overexpressed on tumors, leading to immune resistance, whereas blockade of $\mathrm{B} 7-\mathrm{H} 1$ or PD-1 enhances antitumor immunity. B7-H1 expression in renal cancer correlates with poor clinical prognosis $^{6-8}$.

CTLA-4-specific antibody, inhibiting the CTLA-4mediated immune checkpoint, induces clinical regressions in patients with advanced melarelated toxicity ${ }^{9-12}$.

CTLA-4-specific antibodies induce tumor responses in renal and prostate cancers ${ }^{13,14}$.

A therapeutic vaccine demonstrated durable complete responses in some women with HPV-16+ vulvar intraepithelial neoplasias, a disease that normally has a spontaneous regression rate of less than $2 \%{ }^{15}$. noma but also causes immune-
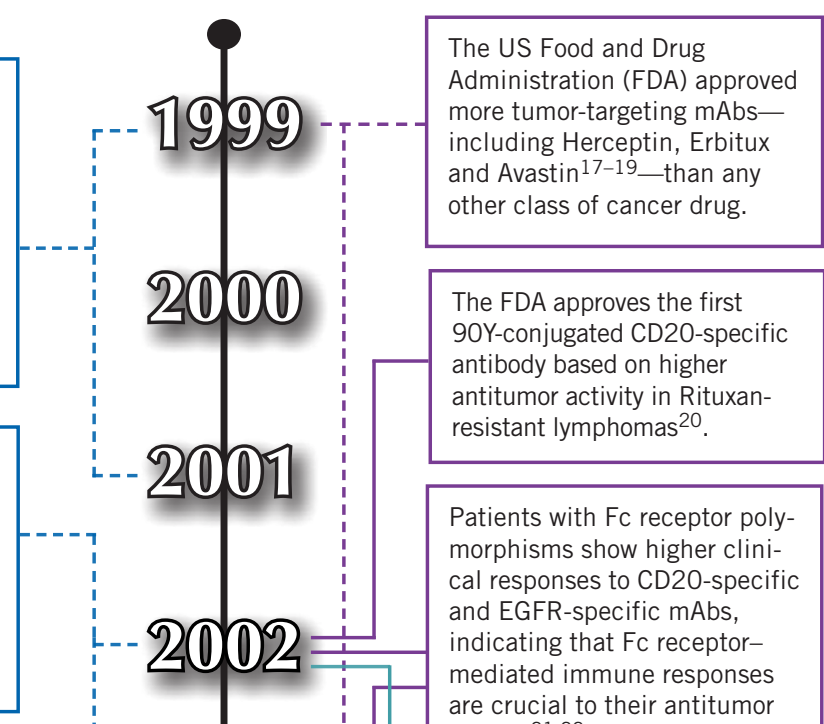

\section{The FDA approves the first 90Y-conjugated CD20-specific antibody based on higher antitumor activity in Rituxan- resistant lymphomas 20}

The results of the first cancer vaccine to show a survival benefit in a phase 3 trial are reported. Sipileucil-T (Provenge), a dendritic cell vaccine loaded with an antigen-GM-CSF conjugate, confers a four-month overall survival advantage in men with advanced castrate-resistant prostate cancer ${ }^{16}$ and is approved by the FDA.

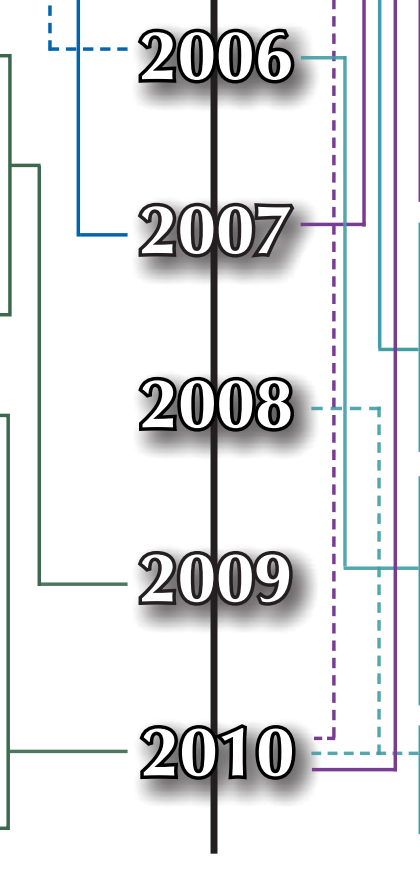

Patients with Fc receptor polymorphisms show higher clinical responses to CD20-specific and EGFR-specific mAbs, indicating that Fc receptormediated immune responses are crucial to their antitumor activity 21,22 .

A CTLA-4-specific mAb is the first agent in history to provide a survival advantage in patients with advanced melanoma in a phase 3 trial $^{23}$.

A PD-1-specific mAb induces frequent tumor regressions in patients with advanced melanoma, renal cancer, lung cancer and colon cancer with very low rates of toxicity. Response correlates with tumor membrane expression of $\mathrm{B} 7-\mathrm{H}^{29}$.

The first clear-cut benefit of Herceptin conjugated with an antimicrotubule agent was seen in patients with 'naked' Herceptin-resistant breast tumors 30 .

Two studies show for the first time that adoptive $T$ cell therapy for patients with advanced melanoma using in vitroexpanded T cells can cause tumor regressions ${ }^{24,25}$.

1. Nishimura, H., Nose, M., Hiai, H., Minato, N. \& Honjo, T. Immunity 11, 141-151 (1999).

2. Nishimura, H. et al. Science 291, 319-322 (2001).

3. Dong, H., Zhu, G., Tamada, K. \& Chen, L. Nat. Med. 5, 1365-1369 (1999).

4. Latchman, Y. et al. Nat. Immunol. 2, 261 268 (2001).

5. Tseng, S.Y. et al. J. Exp. Med. 193, 836-846 (2001).

6. Dong, H. et al. Nat. Med. 8, 793-800 (2002).

7. Iwai, Y. et al. Proc. Natl. Acad. Sci. USA 99, 12293-12297 (2002).

8. Thompson, R.H. et al. Proc. Natl. Acad. Sci. USA 101, 17174-17179 (2004).

9. Hodi, F.S. et al. Proc. Natl. Acad. Sci. USA 100, 4712-4717 (2003).

10. Phan, G.Q. et al. Proc. Natl. Acad. Sci. USA 100, 8372-8377 (2003).

11. Attia, P. et al. J. Clin. Oncol. 23, 6043-6053 (2005).

12. Beck, K.E. et al. J. Clin. Oncol. 24, 22832289 (2006).

13. Small, E.J. et al. Clin. Cancer Res. 13, 18101815 (2007).

14. Yang, J.C. et al. J. Immunother. 30, 825-830 (2007).

15. Kenter, G.G. et al. N. Engl. J. Med. 361, 1838-1847 (2009).

16. Kantoff, P.W. et al.; IMPACT Study Investigators. N. Engl. J. Med. 363, 411-422 (2010).

17. Slamon, D.J. et al. N. Engl. J. Med. 344, 783-792 (2001).

18. Cunningham, D. et al. N. Engl. J. Med. 351, 337-345 (2004).

19. Hurwitz, H.I. et al. J. Clin. Oncol. 23, 35023508 (2005).

20. Witzig, T.E. et al. J. Clin. Oncol. 20, 24532463 (2002).

21. Cartron, G. et al. Blood 99, 754-758 (2002).

22. Zhang, W. et al. J. Clin. Oncol. 25, 37123718 (2007).

23. Hodi, F.S. et al. N. Engl. J. Med. $\mathbf{3 6 3}, 711-$ 723 (2010).

24. Yee, C. et al. Proc. Natl. Acad. Sci. USA 99 16168-16173 (2002).

25. Dudley, M.E. et al. Science $\mathbf{2 9 8}, \mathbf{8 5 0 - 8 5 4}$ (2002).

26. Morgan, R.A. et al. Science 314, 126-129 (2006).

27. Till, B.G. et al. Blood 112, 2261-2271 (2008).

28. Kochenderfer, J.N. et al. Blood 116, 40994102 (2010).

29. Brahmer, J.R. et al. J. Clin. Oncol. 28, 31673175 (2010).

30. Krop, I.E. et al. J. Clin. Oncol. 28, 26982704 (2010).

Bulk T cells transduced with $T$ cell receptor genes are used to treat patients with melanoma, bypassing the need to expand tumor-specific T cells from patients with cancer ${ }^{26}$.
Drew Pardoll is at the Sidney Kimmel

Cancer Center, Johns Hopkins University,

Baltimore, Maryland, USA.

e-mail: dpardol1@jhmi.edu

Engineered T cells expressing chimeric antigen receptors induce clinical responses in patients with B cell lymhomas $27,28$. 